\title{
Econometric Study of Technology Innovation Performance in China
}

\author{
Miaoxu $\operatorname{Han}^{1, a}$ \\ ${ }^{1}$ University of Alberta,Edmonton,Alberta T5J 4P6, Canada \\ amiaoxu@ualberta.ca
}

Keywords: national innovation system, regional innovation system, innovation performance

\begin{abstract}
This paper adopts modern metering methods such as spatial statistics, spatial econometrics, spatial filtering, random leading edge model with heterogeneity, quantile regression, panel unit root, panel co-integration, and so on, to complete the research on the direct performance of regional technological performance; on the basis on theoretical analysis, this paper builds conduct model of regional technological innovation into national macro economic development and co-integration model of Chinese small macroscopic econometrics, which is undoubtedly innovative in the aspect of technological innovation performance evaluation.
\end{abstract}

\section{Introduction}

To study the phenomenon and laws of regional technological innovation system is an important part to promote regional technological innovation, an important measure to realize the regional sustainable and harmonious development in China, and also an important step to realize regional development strategy in our country. To build effective regional technological innovation system, the investment of regional technological innovation is necessary. On the basis of theoretical analysis, this paper analyzes and evaluates the influence of regional technological investment on the main macroeconomic variables in our country, and investigates regional technological innovation performance against the background of national macroeconomic development; comparing with the existing literature on technological innovation performance evaluation, this paper undoubtedly has great significance in the aspect of technological innovation performance evaluation.

\section{Regional technological innovation performance}

Performance is a polyseme, which has six difference meanings in English, and the common meaning refers to manifestation, achievement or result (Luo Yafei, 2010P58) Ilgen and Schneider (1991) believe that performance refer to what individuals or organizations do. Campbell et al. (1993) think that performance is a concept with multiple dimensions, and there is no single performance variable. Xiao Mingzheng (2007) considers that the connotation of performance has three aspects: the first refers to effect, and the degree to which the goal reaches, which is the appearance form of performance; the second refers to the relationship between investment and production; the third refers to benefit, which is the economic benefit, social benefit and time benefit to organizations or individuals by the final results. Therefore, performance can be understood as the achievements, efficiency and benefits organizations or individuals gained under certain external circumstances. In the research process, this paper focuses on the indirect performance evaluation of regional technological innovation, which is the issue of the indirect performance evaluation of regional technological innovation; thereinafter, the influence of regional technological innovation on national macro economy, or the macroeconomic effect, of regional technological innovation on national macro economy, is abbreviated as macro performance of regional technological innovation. 


\section{Analytical model building of macro performance of Chinese regional technological innovation}

\section{Co-integration model building of Chinese macro econometrics}

1. Theoretical basis for the model

(1) Relevant theories of the model. This paper applies the co-integration estimation method made by Gregory and Hansen (1996), which has the function of internal structural mutation inspection, so as to catch the mutation phenomenon that the model parameters may exist.

(2) Parameter estimation method. Gregory and Hansen put forward a method to estimate parameters of co-integration measurement model based on OLS; with this method, the discontinuous behaviors in economic behaviors can be caught, which refers to the structural mutation problem in economic behaviors. The standard co-integration model can be expressed as:

$\mathrm{y}_{1 \mathrm{t}}=\mu+\alpha{ }^{\mathrm{t}} \mathrm{y}_{2 \mathrm{t}}+\varepsilon_{\mathrm{t}} \mathrm{t}=1, \ldots, \mathrm{n}(2-1)$

In the formula (2-1), the variables $\mathrm{y}_{1 \mathrm{t}}, \mathrm{y}_{1 \mathrm{t}}$ are $\mathrm{I}(1)$ variables; while $\varepsilon_{\mathrm{t}}$ is $\mathrm{I}(0)$ variable. When the economic behaviors have such structural changes, they will show in parameters of $\mu$ and $\alpha$, and to catch structural breaking point, dummy variables are set as following:

$$
\varphi_{t \tau}=\left\{\begin{array}{lll}
0 & \text { if } & t \leq[n \tau] \\
1 & \text { if } & t>[n \tau]
\end{array}\right.
$$

In the formula, the parameter $\tau \in(0,1)$ is for the time of structural mutation of economic behavior (relative time), $\mathrm{n}$ for sample length, $[\mathrm{n} \tau]$ for round number of $n \tau$. There are three expression forms of structural mutation in economic behaviors in econometric model, which is shown in Formulas (2-2) to (2-4).

$$
\begin{aligned}
& y_{1 t}=\mu_{1}+\mu_{2} \varphi_{t \tau}+\alpha^{T} y_{2 t}+\varepsilon_{t} \quad t=1, \cdots, n \\
& y_{1 t}=\mu_{1}+\mu_{2} \varphi_{t \tau}+\beta t+\alpha^{T} y_{2 t}+\varepsilon_{t} \quad t=1, \cdots, n \\
& y_{1 t}=\mu_{1}+\mu_{2} \varphi_{t \tau}+\beta t+\alpha_{1}^{T} y_{2 t}+\alpha_{2}^{T} y_{2 t} \varphi_{t \tau}+\varepsilon_{t} \quad t=1, \cdots, n_{(2-4)}
\end{aligned}
$$

In the formula (2-4), $\mu 1$ stands for the constant term before mutation, $\mu 2$ for the variable quantity of the constant term in structural mutation, $\alpha 1$ for the equation slope before mutation, $\alpha 2$ for the variable quantity of the equation slope in mutation.

(3) Main characteristics of the model. Firstly, a small macro econometric co-integration model is an annual macro economic measurement model of supply and demand double oriented model, based on Keynes's national income decision theory and built according to national products and revenue accounting system (SNA). Secondly, the equation design depends on the dual drive of economic theory and data characteristics. In the process of model building, the endogenous and exogenous variables of the model are defined according to economic theory. Thirdly, a small macro econometric model is a co-integration econometric model.

2. Model structure. Small macro econometric co-integration model is divided into seven modules of production module, labor force module, revenue module, consumption module, investment and fixed asset module, price model and foreign trade module;. The total data comes from Statistical data assembly of New China's 60 years, CEInet Statistical Database, Statistical Yearbook of Chinese Science and Technology, Chinese Statistical Yearbook, and so on.

All the models have passed $\mathrm{F}$ test with the significance level of 5\%. The modules of macro econometric co-integration model and the model are as following:

(1) Production module

$$
\begin{aligned}
& \text { LOG(V1) }=25.5321+0.0364 * \mathrm{D} 93 * \mathrm{LOG}(\mathrm{CSPA})+0.2640 * \mathrm{LOG}(\mathrm{KV} 1)-1.7319 * \mathrm{LOG}(\mathrm{L} 1) \\
& \mathrm{LOG}(\mathrm{V} 2)=-13.7444+0.5360 * \mathrm{LOG}(\mathrm{CSPA})+0.3549 * \mathrm{LOG}(\mathrm{KV} 2)+0.3654 * \mathrm{LOG}(\mathrm{L} 2)+[\mathrm{AR}(1)=1.3429,
\end{aligned}
$$

$\operatorname{AR}(2)=-0.5890]$ 
LOG(V3) $=-13.7204+0.3074 *$ LOG(CSPA $)+0.1882 *$ LOG(KV3) + 1.8340*LOG(L3)

$\mathrm{LOG}(\mathrm{GCF})=1.2302+0.8914 * \mathrm{LOG}(\mathrm{IF})-0.1399 * \mathrm{D} 02 * \mathrm{LOG}(\mathrm{IF})+1.5077 * \mathrm{D} 02+$ [AR(1)=0.5147]

OGAP $=-389.2478-1.2398 * \mathrm{GDPE}+0.7711 * \mathrm{~V} 1+1.69856 * \mathrm{~V} 2+1.1226 * \mathrm{~V} 3$

$\mathrm{GDP}=\mathrm{V} 1+\mathrm{V} 2+\mathrm{V} 3 \quad \mathrm{~V} 1 \mathrm{C}=\mathrm{V} 1 / \mathrm{PV} 1 * 100 \quad \mathrm{~V} 2 \mathrm{C}=\mathrm{V} 2 / \mathrm{PV} 2 * 100 \quad \mathrm{~V} 3 \mathrm{C}=\mathrm{V} 3 / \mathrm{PV} 3 * 100$

GDPC $=$ GDP/PGDP*100

$\mathrm{GDPE}=\mathrm{GCF}+\mathrm{CT}+\mathrm{XT}-\mathrm{MT}$

\section{(2) Labor force module}

LOG(L1) = 26.0945-0.0958*LOG(CT(-1))-1.2879*LOG(AP)+0.2828*D00*LOG(AP) -0.2858*D00*LOG(CT)

LOG(L2) $=7.6700+0.4881 *$ LOG(V2) $-0.3319 *$ LOG(UW) $-0.1549 * \mathrm{D} 92$

$\mathrm{LOG}(\mathrm{L} 3)=6.3307+0.3235 * \mathrm{LOG}(\mathrm{CT})+[\mathrm{AR}(1)=1.0810, \quad \mathrm{AR}(2)=-0.6365] \mathrm{L}=\mathrm{L} 1+\mathrm{L} 2+\mathrm{L} 3$

(3)revenue module

$\mathrm{LOG}(\mathrm{YA})=4.8019+0.4276 * \mathrm{LOG}(\mathrm{YA}(-1))+0.5344 * \mathrm{LOG}(\mathrm{V} 1 / \mathrm{L} 1)+0.0840 * \mathrm{D} 89+[\mathrm{AR}(1)=0.5122]$

LOG(YU)=-0.5314 + 0.6361*LOG(YU( - 1)) + 0.4308*LOG(UW) - 0.0121*D00*LOG(UW)- 0.1277*D95

$\mathrm{LOG}(\mathrm{UW})=6.9605+0.2860 * \mathrm{LOG}(\mathrm{UCPI}(-1))+0.7359 * \mathrm{LOG}(\mathrm{GDP} / \mathrm{L})+0.3184 * \mathrm{D} 95 * \mathrm{LOG}(\mathrm{GDP} / \mathrm{L})+[\mathrm{AR}(1)=0.6648]$

LOG $(G O R V)=2.2222+0.5794 *$ LOG(GDP)-8.1728*D93+0.7545*D93*LOG(GDP)+[AR(1)=1.1110, AR(2)= $-0.6093]$

$\mathrm{LOG}(\mathrm{GEXE})=-0.2090+0.2131 * \mathrm{LOG}(\mathrm{GEXE}(-1))+0.8219 * \mathrm{LOG}(\mathrm{GORV})-0.1039 * \mathrm{D} 04$

(4) Consumption module

LOG(CRAP) $=0.2488+0.6984 *$ LOG(CRAP(-1))+0.2669*LOG(YA)-0.7186*D92*LOG(CRAP(-1)) + $0.6941 * \mathrm{D} 92 *$ LOG(YA)

$\mathrm{LOG}(\mathrm{CRNP})=-1.6411+0.3065 * \operatorname{LOG}(\mathrm{CRNP}(-1))+0.9886 * \mathrm{LOG}(\mathrm{YU})+0.1018 * \mathrm{D} 85$ - 0.0454*@TREND

$\mathrm{LOG}(\mathrm{CP})=-4.7004+1.5834 * \mathrm{LOG}(\mathrm{GORV})-0.9031 * \mathrm{D} 93 * \mathrm{LOG}(\mathrm{GORV})+7.8397 * \mathrm{D} 93+[\mathrm{AR}(1)=0.8453, \quad \mathrm{AR}(2)$ $=-0.4096]$

$\mathrm{RC}=\mathrm{CRAP} * \mathrm{AP} / 10000$

$\mathrm{RCC}=\mathrm{RC} / \mathrm{RCPI} * 100$

$\mathrm{UC}=\mathrm{CRNP} * \mathrm{NP} / 10000$

$\mathrm{UCC}=\mathrm{UC} / \mathrm{UCPI} * 100$

$\mathrm{RUC}=\mathrm{RC}+\mathrm{UC}$

RUCC $=$ RUC/PCR $* 100 \quad \mathrm{CT}=\mathrm{RUC}+\mathrm{CP}$

$\mathrm{CTC}=\mathrm{RCC}+\mathrm{UCC}+\mathrm{CP} / \mathrm{PR} * 100$

(5)Investment and fixed asset module

LOG(IF) $=-1.0727+1.0430 *$ LOG(CT) $-1.0347 *$ D02*LOG(CT(-2)) + 1.1798*D02*LOG(GEXE(-1))

LOG(IF1)=0.3228+0.9820*LOG(IF1(-1))-5.075*D02+1.3317*D02*LOG(IF)-1.3346*D02*LOG(IF1(-1))

LOG(IF2) $=-3.1461+1.2041 *$ LOG(IF) $-0.0158 *$ D96*LOG(IF) + [AR(1) $=0.8543]$

$\mathrm{LOG}(\mathrm{IF} 3)=0.6992+0.8767 * \mathrm{LOG}(\mathrm{IF})+0.0146 * \mathrm{D} 96 * \mathrm{LOG}(\mathrm{IF})+[\mathrm{AR}(1)=0.7989]$

$\mathrm{KV} 1=0.95 * \mathrm{KV} 1(-1)+\mathrm{IF} 1 \mathrm{C} \quad \mathrm{KV} 2=0.95 * \mathrm{KV} 2(-1)+\mathrm{IF} 2 \mathrm{C} \quad \mathrm{KV3}=0.95 * \mathrm{KV} 3(-1)+\mathrm{IF} 3 \mathrm{C}$

IF1C $=$ IF1/PI*100 IF2C $=$ IF2/PI*100

IF3C $=$ IF3/PI*100 IFC=IF1C + IF2C + IF3C

Table 2-1 Endogenous variable of macroeconomic model

\begin{tabular}{|l|l|l|}
\hline Variable & \multicolumn{1}{|c|}{ Implication } & Unit \\
\hline AP & Rural population & Ten thousand \\
\hline EXRA & Exchange rate (1 US dollar = RMB) & \\
\hline NP & Urban population & Ten thousand \\
\hline PIAM & Prize indices of agricultural means of production (1980=100) & \\
\hline PPI & Purchase prize indices of raw materials, fuel, power (1990=100) & \\
\hline OECDP & GDP comprehensive deflator of all the countries in OECD & One billion US dollars \\
\hline WD & $\begin{array}{l}\text { World demand (import volume of world commodities and service (US dollar } \\
\text { constant price in 2005)) }\end{array}$ & \\
\hline
\end{tabular}


The standard of model evaluation is Root Means Square, RMS, and the computational formula is (Zhao Guoqing, Yang Jian, 2003P81):

$$
R M S_{i}=\sqrt{\frac{1}{T} \sum_{i=1}^{T}\left[\frac{F_{i t}-A_{i t}}{A_{i t}}\right]^{2}}
$$

In the formula (2-5), Fit is for estimated value, Ait for actual value, $\mathrm{T}$ for sample interval length. Obviously, when $\mathrm{RMS}_{\mathrm{i}}=0$, it means the estimated value of endogenous variable i matches the actual observed value completely. The Root Means Square of endogenous variable in all the behavior equation is shown in Table 2-3.

Table 2-2 Root Means Square of endogenous variable

\begin{tabular}{|c|c|c|c|c|c|}
\hline Variable & Implication & Unit & Variable & Implication & Unit \\
\hline $\mathrm{CP}$ & $\begin{array}{l}\text { Government consumption (current } \\
\text { price) }\end{array}$ & 2.2584 & MT & Gross import (current price) & 7.9429 \\
\hline CRAP & $\begin{array}{l}\text { Per capita consumption expenditure } \\
\text { of rural residents (current price) }\end{array}$ & 1.6145 & PCR & Consumer price index & 0.3177 \\
\hline CRNP & $\begin{array}{l}\text { Per capita consumption expenditure } \\
\text { of urban residents (current price) }\end{array}$ & 2.0065 & PGDP & GDP deflator & 2.3771 \\
\hline CT & Total consumption (current price) & 0.0010 & PI & Fixed asset investment price index $(1978=100)$ & 3.2078 \\
\hline$\overline{\text { GCF }}$ & $\begin{array}{l}\text { Gross capital formation (current } \\
\text { price) }\end{array}$ & 2.8861 & PR & General price index of retail sales & 3.7325 \\
\hline GEXE & $\begin{array}{l}\text { Expenditure of national financial } \\
\text { statements in this level (current } \\
\text { price) }\end{array}$ & 3.0498 & RCPI & Consumer price index of rural residents & 0.9339 \\
\hline GORV & Fiscal revenue (current price) & 1.916 & UCPI & Consumer price index of urban residents & 0.7770 \\
\hline IF1 & $\begin{array}{l}\text { Fixed-asset investment of the } \\
\text { primary industry (current price) }\end{array}$ & 6.8767 & UW & Average wage & 4.2117 \\
\hline IF2 & $\begin{array}{l}\text { Fixed-asset investment of the } \\
\text { secondary industry (current price) }\end{array}$ & 5.0358 & V1 & The first industrial added value (constant price) & 4.9969 \\
\hline IF3 & $\begin{array}{l}\text { Fixed-asset investment of the third } \\
\text { industry (current price) }\end{array}$ & 3.3620 & V2 & $\begin{array}{l}\text { The second industrial added value (constant } \\
\text { price) }\end{array}$ & 3.5292 \\
\hline IF & $\begin{array}{l}\text { Fixed-asset investment of the whole } \\
\text { society (current price) }\end{array}$ & 2.2380 & V3 & The third industrial added value (constant price) & 2.1352 \\
\hline L1 & $\begin{array}{l}\text { Number of employees in the first } \\
\text { industry }\end{array}$ & 0.7917 & $\mathrm{XT}$ & Gross export (current price) & 4.4419 \\
\hline L2 & $\begin{array}{l}\text { Number of employees in the second } \\
\text { industry }\end{array}$ & 3.1798 & YA & $\begin{array}{l}\text { Per capita net income of rural households } \\
\text { (current price) }\end{array}$ & 1.2823 \\
\hline L3 & $\begin{array}{l}\text { Number of employees in the third } \\
\text { industry }\end{array}$ & 0.9924 & YU & $\begin{array}{l}\text { Per capita net income of urban households } \\
\text { (current price) }\end{array}$ & 3.8208 \\
\hline
\end{tabular}

From Table 2-3, it can be seen that except for the three variables of Fixed-asset investment of the primary industry, Fixed-asset investment of the secondary industry, and Fixed-asset investment of the third industry, error rates of the Root Means Square of the other endogenous variables are under 5\%, which occupies more than $90 \%$ of all the endogenous variables, which indicates that the prediction accuracy of the model's sample interval is high, the total imitative effect of model system is good, and this model can be taken to make situational analysis.

C. Connection of regional technological innovation and Chinese macro econometric model

The connective way of regional research and development innovation activities and national macro econometric model is through the connecting mechanism of innovation knowledge produced by regional knowledge production function influencing the research and development knowledge stock, 
and the national research and development knowledge stock influencing national macro economic activities, whose theoretical basis is the endogenous economic growth theory and knowledge spillover theory. The regional knowledge production function to be used is:

$\log \left(\right.$ paap $\left._{i t}\right)=\alpha_{i t}+\beta_{1} \cdot \log \left(n\right.$ stp $\left._{i t}\right)+\beta_{2} \cdot \log \left(\right.$ rdep $\left._{i t}\right)+\beta_{3} \cdot \log \left(r f d i_{i t}\right)+\beta_{4} \cdot \log \left(\right.$ rim $\left._{i t}\right)+\varepsilon_{i t}(6-6)$

According to the analysis above, regional technological innovation activities have spacial correlation; therefore model (6-6) cannot take traditional method (such as OLS) to make regression analysis; otherwise, model will produce specification error (Anselin, 1988). Under this circumstance, the proper measurement model is:

$\log \left(\right.$ paap $\left._{i t}\right)=\alpha_{i t}+\rho \cdot W \cdot \log \left(\right.$ paap $\left._{i t}\right)+\beta \cdot \log \left(X_{i t}\right)+\varepsilon_{i t}(6-7)$

$\log \left(\right.$ paap $\left._{i j}\right)=\alpha_{i t}+\beta \cdot \log \left(X_{i j}\right)+\varepsilon_{i t} \quad \varepsilon_{i t}=\rho \cdot W \cdot \varepsilon_{i t}+u_{i t}(6-8)$

In formula (6-7), vector quantity X stands for the corresponding explanatory variable of model (6-6) or first-order lagged variable, and $\beta$ for the corresponding coefficient matrix. Model (6-7) is called as panel spatial lag model, which can be used to explore and study whether the research object has the spillover effect in a region; model (6-8) is called as panel spatial error model, which is used for analyzing and studying whether the relations of the research object among regions can be embodied through error term (Elhorst, 2003).

The model above can be used to measure the quantitative relation between regional patent application amount paap ${ }_{\text {it }}$ and its influencing factors, so as to calculate the national patent application amount of that year paap, which can be shown with formula (2-9):

$$
\text { paap }_{t}=\sum_{i=1}^{n} \text { paap }_{i t}(2-9)
$$

In formula (2-9), $\mathrm{n}$ is for the number of regions, $\mathrm{t}$ for year. After gaining the national patent application amount paap ${ }_{t}$, formula (2-10) can be used to express the relation between national patent application amount paap ${ }_{t}$ and the national innovation knowledge stock cspa, which can be expressed with non-parametric econometric model:

$\operatorname{cspa}_{t}=m\left(\right.$ paap $\left._{t}\right)+\sigma\left(\right.$ paat $\left._{t}\right) \varepsilon_{t}$

$(2-10)$

In formula (2-10), $\mathrm{m}\left(\right.$ paap $\left._{\mathrm{t}}\right)$ is unknown function, $\mathrm{m}\left(\mathrm{paap}_{\mathrm{t}}\right)=\mathrm{E}\left(\mathrm{cspa}_{\mathrm{t}} \mid \mathrm{paap}_{\mathrm{t}}\right)$; $\mathrm{\varepsilon t}$ is the sequence with mean value as 0 , variance as 1 , independent from explanatory variable; random error term $\mu 1=\sigma\left(\right.$ paap $\left._{t}\right) \varepsilon_{t}$, with conditional variance as $\sigma^{2}\left(\right.$ paap $\left._{t}\right)=E\left(\mu^{2} \mid p_{a a p_{t}}\right)$. Model (2-10) has many ways for estimation and this chapter adopts non-parametric kernel estimation to estimate it (Sun Jian, 2010).

Regional knowledge production function suits panel time-space fixed effect model, whose specific form is:

$\log \left(\right.$ paap $\left._{i t}\right)=\alpha+\rho \cdot W \cdot \log \left(\right.$ paap $\left._{i t}\right)+\beta \cdot \log \left(X_{i t}\right)+\mu_{i}+\theta_{t}+\varepsilon_{i t}(2-11)$

In the model (2-11), $\mu$ i is the Region-Specific Fixed Effect in region i, which refers to the influence of the regional characteristics in the region $\mathrm{i}$ on regional technological innovation activities after controlling other explanatory variables. $\theta t$ is the Time-Specific Fixed Effect in the year of $t$, which refers to the fixed influence of region's characteristics in the year of $t$ on regional technological innovation activities after controlling other explanatory variables. 
Table 2-3 Panel model's test results

\begin{tabular}{|c|c|c|c|c|}
\hline Test model & Test type & $\begin{array}{c}\text { Test } \\
\text { statistical } \\
\text { values }\end{array}$ & $\begin{array}{l}\text { Proba } \\
\text { bility }\end{array}$ & $\begin{array}{c}\text { Likelihood } \\
\text { function log koc }\end{array}$ \\
\hline \multirow{3}{*}{$\begin{array}{c}\text { POOL } \\
\text { estimation } \\
\text { test(1) }\end{array}$} & LM test no spatial lag & 8.6936 & 0.003 & \multirow{3}{*}{-209.2131} \\
\hline & Robust LM test no spatial lag & 0.0523 & 0.819 & \\
\hline & LM test no spatial error & 26.2897 & 0.000 & \\
\hline \multirow{4}{*}{$\begin{array}{l}\text { Spatial fixed } \\
\text { effect lag or } \\
\text { error test(2) }\end{array}$} & LM test no spatial lag & 78.6385 & 0.000 & \multirow{4}{*}{-21.5132} \\
\hline & robust LM test no spatial lag & 109.9862 & 0.000 & \\
\hline & LM test no spatial error & 14.6663 & 0.000 & \\
\hline & robust LM test no spatial error & 46.0140 & 0.000 & \\
\hline \multirow{4}{*}{$\begin{array}{c}\text { Space-time } \\
\text { fixed effect lag } \\
\text { or error test(3) }\end{array}$} & LM test no spatial lag & 22.3277 & 0.000 & \multirow{4}{*}{ 38. 8193} \\
\hline & robust LM test no spatial lag & 6.0684 & 0.014 & \\
\hline & LM test no spatial error & 18.4924 & 0.000 & \\
\hline & robust LM test no spatial error & 2.2330 & 0.135 & \\
\hline
\end{tabular}

Model (2-11) takes Elhorst(2003)'s second order maximum likelihood estimation to estimate. Table (2-5) shows the situation of lag explanatory variables, without listing time and space fixed effect; as for the model, $\mathrm{R}^{2}=0.9741$, corr $^{2}=0.8339$ and the likelihood function log koc is 38.8193. Table (2-6) shows the situation of model explanatory variables having no lag terms, without listing time and space fixed effect; as for the model, $\mathrm{R}^{2}=0.9757$, corr $^{2}=0.8446$ and the likelihood function log koc is 32.8199 .

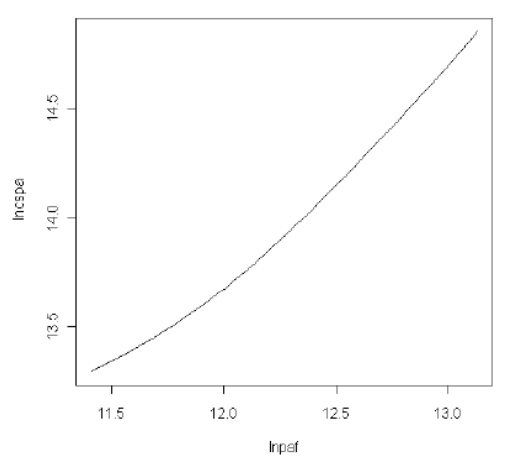

Figure 2-1 Model (2-10) non-parametric estimation results

According to the fundamentals of macro econometric model and considering the latest parameter estimation method in the econometric theory, this paper builds regional- macro econometric co-integration model of China, which can be used for the simulation study of the influence of regional technological innovation activities in China on Chinese macro economy’s main variables.

\section{Conclusions}

The study finds out that all the environmental factors influencing Chinese regional technological innovation efficiency are steady variables, and there is co-integration relationship between investment and output variables. Other factors such as government funding, financing institutions' support have different influencing directions and significance degree on the technological innovation efficiency in the whole world and the three regions.

\section{References}

[1] Scientific and Technological Progress and Countermeasures, 2014 Table of contents [J]. Scientific and Technological Progress and Countermeasures, 2014,24:1-16. 
[2] Chen Sihui, Wang Yaxin. Empirical Study on Provincial Differences and Investment Performance of Hi-tech Industry in China [J]. Economic Geography, 2015,02:120-126.

[3] Cheng Zhonghua, Liu Jun. Industrial Agglomeration, Spatial Spillover and Manufacturing Industry's Innovation -- Spatial Econometric Analysis Based on Data of Chinese Cities [J]. Journal of Shanxi University of Finance and Economics,2015,04:34-44.

[4] Yu Yong, Chen Long, Wang Xiao. Measurement and Evaluation of Innovation Performance of Regional Hi-tech Industry in China -- Empirical Study Based on Factor Analysis and Spatial Econometric Model [J]. Journal of Xi'an Institute of Finance and Economics,2015,02:39-46.

[5] Wang Peng, Zeng Kun. Spatial Econometric Study on the Influence of Innovation Environmental Factors on Regional Innovation Efficiency [J]. Journal of Guizhou University of Finance and Economics,2015,02:74-83.

[6] Wu Yuming. Spatial Panel Econometric Analysis of Industry-academy Cooperation and Innovation Performance [J]. Scientific Research Management, 2015,04:118-127. 